\title{
Prevalence of Gastrointestinal Helminthiasis in Horses and Donkeys of Hawassa District, Southern Ethiopia
}

\author{
Mesfin Mathewos $\mathbb{D}^{1},{ }^{1}$ Dawit Girma, ${ }^{1}$ Haben Fesseha ${ }^{D},{ }^{1}$ Metages Yirgalem, ${ }^{2}$ \\ and Eyob Eshetu ${ }^{1}$ \\ ${ }^{1}$ School of Veterinary Medicine, Wolaita Sodo University, P.O. Box: 138, Wolaita Sodo, Ethiopia \\ ${ }^{2}$ School of Veterinary Medicine, Haramaya University, PO. Box: 138, DireDawa, Ethiopia \\ Correspondence should be addressed to Haben Fesseha; tseyon.h@gmail.com
}

Received 6 November 2020; Revised 15 March 2021; Accepted 5 April 2021; Published 8 May 2021

Academic Editor: Bockline Omedo Bebe

Copyright (c) 2021 Mesfin Mathewos et al. This is an open access article distributed under the Creative Commons Attribution License, which permits unrestricted use, distribution, and reproduction in any medium, provided the original work is properly cited.

\begin{abstract}
Background. Gastrointestinal helminth parasite infection is a major influencing factor against the profitability of working equines all over the world. Methods. A cross-sectional study was conducted to determine the prevalence of gastrointestinal tract (GI) helminths and assess the associated risk factors in donkeys and horses in the Hawassa district. A total of 214 fecal samples were collected from randomly selected equines (112 donkeys and 102 horses) and examined for the presence of eggs of GI helminths using standard coprological techniques. Results. According to the current study, the prevalence of GI helminths in equine was $78.5 \%(168 / 214)$ and the highest prevalence was reported in donkeys $92 \%(103 / 112)$ as compared to horses 63\% (65/102). Out of 168 positive samples, the different species of parasites were identified, namely, Strongyle species 120 (56.1\%), Strongyloides westeri 76 (35.5\%), Parascaris equorum 54 (25.2\%), Anoplocephala perfoliata 34 (15.8\%), Oxyuris equi 20 (9.3\%), Fasciola hepatica 18 (8.8\%), Gastrodiscus species 12 (5.6\%), and Dictyocaulus arnfieldi 4 (1.8\%). There was a strong association between the prevalence of GI helminths and factors such as the species of equine, body condition scores, and feed type $(p<0.05)$. However, no significant association $(p>0.05)$ was observed between the prevalence of GI helminths and putative risk factors such as age, sex, housing, and water source. The coproculture performed on 30 pooled fecal samples revealed that Cyathostomes species, Strongylus vulgaris, and Strongylus edentatus were the major helminth parasites of donkeys and horses. Conclusion. The frequency of gastrointestinal helminths in equine species was high, especially in donkeys. Hence, strategic deworming using broad-spectrum antihelminthic drugs and a rotational grazing program should be implemented to control and prevent the diseases.
\end{abstract}

\section{Introduction}

Donkeys (Equus asinus) and horses (Equus caballus) are among the early domesticated equines that have been around as long as 3000 years ago [1]. The world equine population is estimated at about 59 million horses, 52 million donkeys, and 15 million mules [2]. More than $97 \%$ of the world's donkey and mule populations and over $72 \%$ of the world's horse population are found in developing countries and specifically kept for the draft purpose [3,4]. In Africa, the donkey and Horse population are estimated to be 13.7 and 9 million, respectively [5], whereas Ethiopia has more than 8 million donkeys, the second-largest donkey population in the world next to China, more than 2 million horses, and over 350,000 mules [6]. In Ethiopia, the low level of development of the road transport network and the rough terrain of the country makes equines the most valuable, appropriate, and affordable pack animals under the smallholder farming system $[3,7]$.

Horses, donkeys, and mules are extensively used, particularly in rural socioeconomic activities $[4,8]$. Horses are transport animals, used for riding as well as for rural and urban transport. Other important working animals include mules that are mainly used in the hilly areas for packing and riding and playing an important role in rural and periurban communities providing transport at low cost. Donkeys are mainly used to breed mules and light transport in the 
mountains $[3,4,9]$. Despite all these, donkeys and horses are prone to several infectious and noninfectious diseases. The care and management provided for equines are very low, and relatively less attention is given to donkeys which is far below to what it deserves $[3,10,11]$. Among these diseases, they are hosts to a great number of gastrointestinal parasite species [12].

Gastrointestinal parasitism is identified as one of the most important problems for equids in developing countries [13], and it affects the health and working performance of donkeys and horses worldwide. Gastrointestinal helminths cause various degrees of damage depending on the species and nutritional and immune status of equines. They decrease the performance and productivity in the animals, mainly the reduction of body weight or failure to gain weight, or even increase the mortality in acute cases [14].

Studies conducted in Ethiopia and Mexico estimate the prevalence of endoparasite infections at over $90 \%$ in horses [15-17] and over $80 \%$ in donkeys [18-20]. The most commonly identified gastrointestinal helminths of equines in different parts of the country include Strongyle, Cyathostomess, Triodontophorus species, Strongyloides westeri, Parascaris equorum, Dictyocaulus arnfieldi, Oxyuris equi, Gastrodiscus, and Fasciola species [21]. However, information regarding the prevalence and type of internal parasites affecting equines has not been recorded well in the southern part of Ethiopia in general and in the Hawassa district in particular. Therefore, this study was conducted to determine the prevalence of gastrointestinal helminth parasites and associated risk factors in horses and donkeys in the study area.

\section{Materials and Methods}

2.1. Study Area. The study was carried out from October 2019 to May 2020 in and around Hawassa. Hawassa is located $273 \mathrm{~km}$ south of Addis Ababa via Bishoftu, $130 \mathrm{~km}$ east of Sodo, and $75 \mathrm{~km}$ north of Dilla at a latitude of $7^{\circ} 04^{\prime} \mathrm{N}$ and a longitude $38^{\circ} 31^{\prime} \mathrm{E}$ on the escarpment of the Great Rift Valley. The altitude ranges from 1650 to $1700 \mathrm{~m}$ above sea level. The mean annual rainfall and temperature are 900-1100 $\mathrm{mm}$ and $27^{\circ} \mathrm{C}$, respectively [22] (Figure 1).

2.2. Study Animals and Design. A cross-sectional study was conducted on 214 randomly selected indigenous breeds of donkeys and horses to determine the prevalence and potential risk factor of gastrointestinal helminths using the coprological examination. Factors such as species, sex, age, body condition score (BCS), feeding, and water were considered. The study includes horses and donkeys of all age groups and both sexes, kept under extensive management systems. The age of the selected horse and donkeys was determined from birth records and dentition characteristics [24] accordingly, and equines were grouped into three age categories: from 1 to 3 years of age were classified as young, 3-10 years as an adult, and those beyond 10 years as old. Body condition scoring (BCS) of the horses and donkeys were estimated based on the guides described by Elisabeth [25] and classified into poor, medium, and good body conditions.
2.3. Sample Size Determination. The sample size required for this study was determined according to the work of Thrusfield [26]. There was a previous work conducted in this study area where $96 \%$ and $97 \%$ prevalence was taken for donkey and horses, respectively, as the expected prevalence for the determination of sample size. The other determinants considered in sample size determination were 95\% confidence interval and 5\% desired absolute precision. Hence, the sample size is estimated as

$$
\mathbf{N}=\frac{1.96^{2} \mathbf{P}_{\exp }\left(1-\mathbf{P}_{\exp }\right)}{\mathbf{d}^{2}}
$$

where $N=$ required sample size, $\mathrm{P}_{\exp }=$ expected prevalence, $d=$ absolute precision, and $Z=1.96$ at $95 \%$ level of confidence. Thus, a total of 214 cattle were included in the current study.

\subsection{Study Methodology}

2.4.1. Fecal Sample Collection and Handling. Fecal samples were collected directly from the rectum or sometimes from freshly passed feces using plastic gloves in clean plastic bags. Along with sampling, date, name, identification number, age, sex, BCs, feed type, housing condition, and water source were recorded. Then, all fecal samples were transported to the Hawassa University parasitology laboratory for further fecal examination from the selected site by using iceboxes and analyzed in the regional laboratory. Fecal samples were examined using standard parasitological techniques (flotation, sedimentation, and modified Baermann) and examined using $10 \mathrm{x}$ and sometimes $40 \mathrm{x}$ magnification power [27].

The larvae were then identified based on the shape and number of gut cells, relative size, and shape of the larvae's tail. The floatation fluid used in this study was a supersaturated solution of sodium chloride $(\mathrm{NaCl})$ salt prepared in the laboratory according to the procedures given by Zajac and Conboy [28]. Moreover, the eggs were identified using ova identification keys [29, 30].

2.5. Data Management and Statistical Analysis. The collected data from the field were entered into a Microsoft Excel 2016 spreadsheet and analyzed using the STATA version 13 software program. The prevalence was calculated as the number of animals having parasites, divided by the total number of animals examined. The association between the risk factors and the outcome variables was assessed using the chi-square $\left(X^{2}\right)$ test. For all analysis, a $p$ value less than 0.05 was considered as significant.

\section{Results}

3.1. Prevalence of Gastrointestinal Helminths in Donkeys and Horses. The overall prevalence of helminth parasites of equine in the study area was found to be $78.5 \%(168 / 214)$ with a prevalence of $91.9 \%(103 / 112)$ and $63.73 \%(65 / 102)$ in donkeys and horses, respectively (Table 1). 


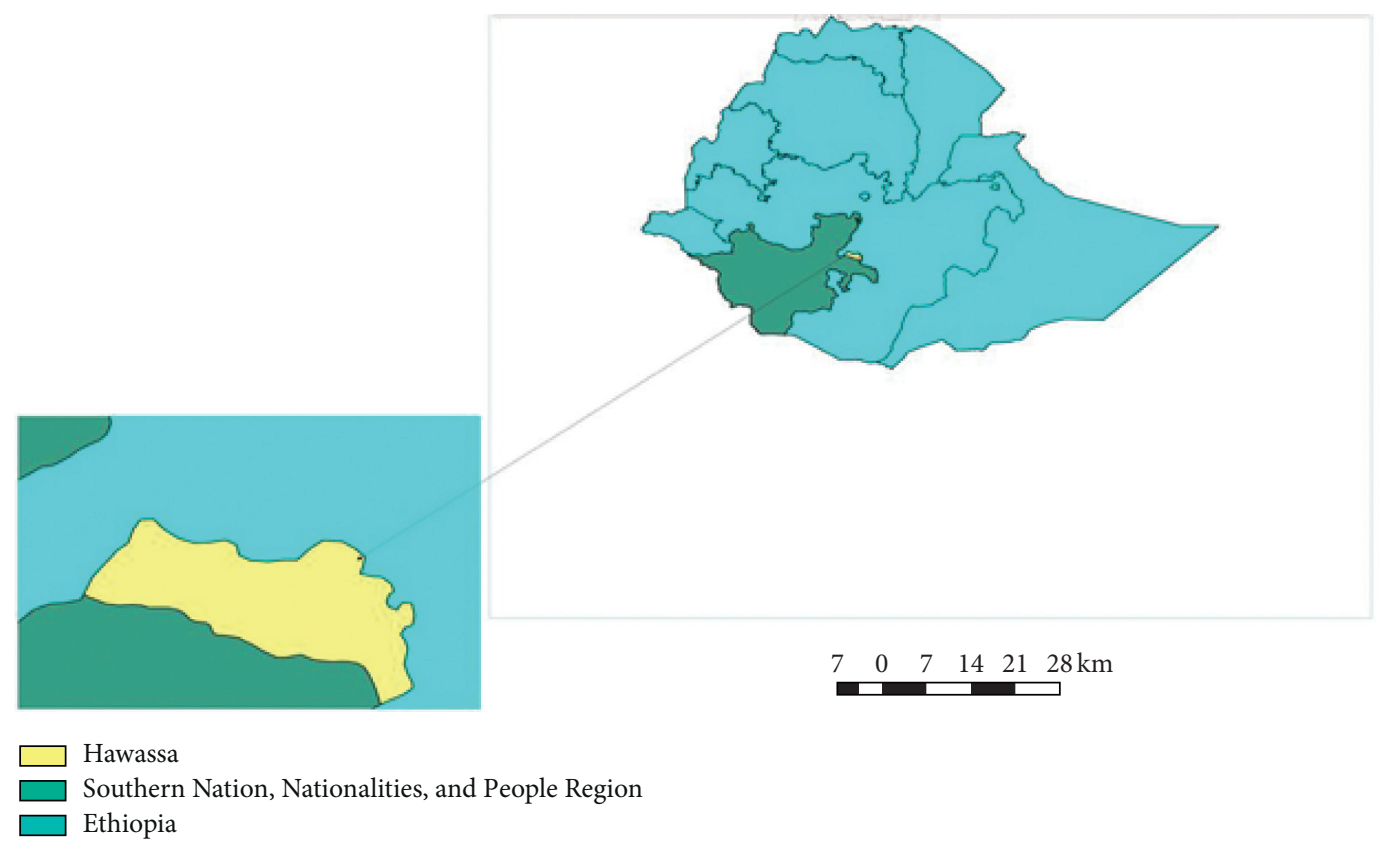

Figure 1: Geographical location map of Hawassa [23].

TABLE 1: Overall prevalence of GI helminth parasites in horses and donkeys.

\begin{tabular}{lccc}
\hline Animal species & No. of examined animals & No. of positives & Proportion (\%) \\
\hline Equines (horse and donkey) & 214 & 168 & 78.5 \\
Donkeys & 112 & 103 & 91.9 \\
Horses & 102 & 65 & 63.7 \\
\hline
\end{tabular}

3.2. Species Distribution of Gastrointestinal Helminths in Donkeys and Horses. The present study revealed that eight different species of GI helminths were identified in this study area. Strongyle species 120 (56.1\%), Parascaris equorum 54 (25.2\%), Strongyloides westeri 76 (35.5\%), Oxyuris equi 20 (9.3\%), Dictyocaulus arnfieldi 4 (1.8\%), Anoplocephala perfoliate, 34 (15.8\%), Fasciola hepatica 18 (8.8\%), and Gastrodiscus species 12 (5.6\%) (Figure 2).

In donkeys, the prevalence of Strongyle species, Strongyloides westeri, and Parascaris equorum was 66\%, $50 \%$, and $34.8 \%$, respectively, while in horses, the prevalence of Strongyle species, Strongyle westeri, and Anoplocephala perfoliata was found to be $45.1 \%, 19.6 \%$, and $15.7 \%$, respectively. In both donkeys and horses, Strongyle species were found as the most prevalent GI helminth parasites in the study area. However, Dictyocaulus arnfieldi were the least prevalent parasites in donkeys with no observation of this parasite in horses during the study period (Table 2).

3.3. Association of Equine Gastrointestinal Helminths in Relation to Different Risk Factors. In this study, there was a significant association $(p<0.05)$ of the prevalence of GI parasites with species of animal, body condition score, and feed type. However, age, sex, housing, and water have no significant association $(p>0.05)$ with the prevalence of GI parasites (Table 3).
3.4. Fecal Culture Output. In the current study, fecal culture was conducted to identify the larvae of nematodes. Strongylus vulgaris (36.6\%) and Cyathostomins species $(36.6 \%)$ were recorded in a higher proportion in horses than in donkeys, whereas a higher proportion of Strongylus edentatus (13.3\%) was recovered from donkeys than horses (Table 4).

\section{Discussion}

Gastrointestinal parasite infection directly affects the health and production of working equines, which contributes to the reduction in their work output and, ultimately, in the income of the owner and the community [31,32]. In this study, the overall prevalence of gastrointestinal helminth was $78.5 \%$, where a higher prevalence of GI parasitism was recorded in donkeys (91\%) than horses (63\%). This finding was lower as compared to the reports of Mezgebu et al. [14], who reported $92.71 \%$ in Gondar, Ethiopia, and Debra et al. [31], who reported $88.8 \%$ in Guder, west Shewa, Ethiopia, Takele and Nibret [33], who reported $88.2 \%$ in Bahirdar, Chemeda et al. [34], who reported 94.0\% in Ambo, Ayele et al. [11], who reported $98.2 \%$ in Dugda Bora district, Tolossa and Ashenafi [7], who reported 92.71\% in Arsi-Bale highland, Gulima [35], and Seyoum et al. [36], who reported 84.4\% in Awi Zone and around Shashemane.

The prevalence of GI helminths reported in the same study area by Ibrahim et al. [37] and Berhanu et al. [38] was 


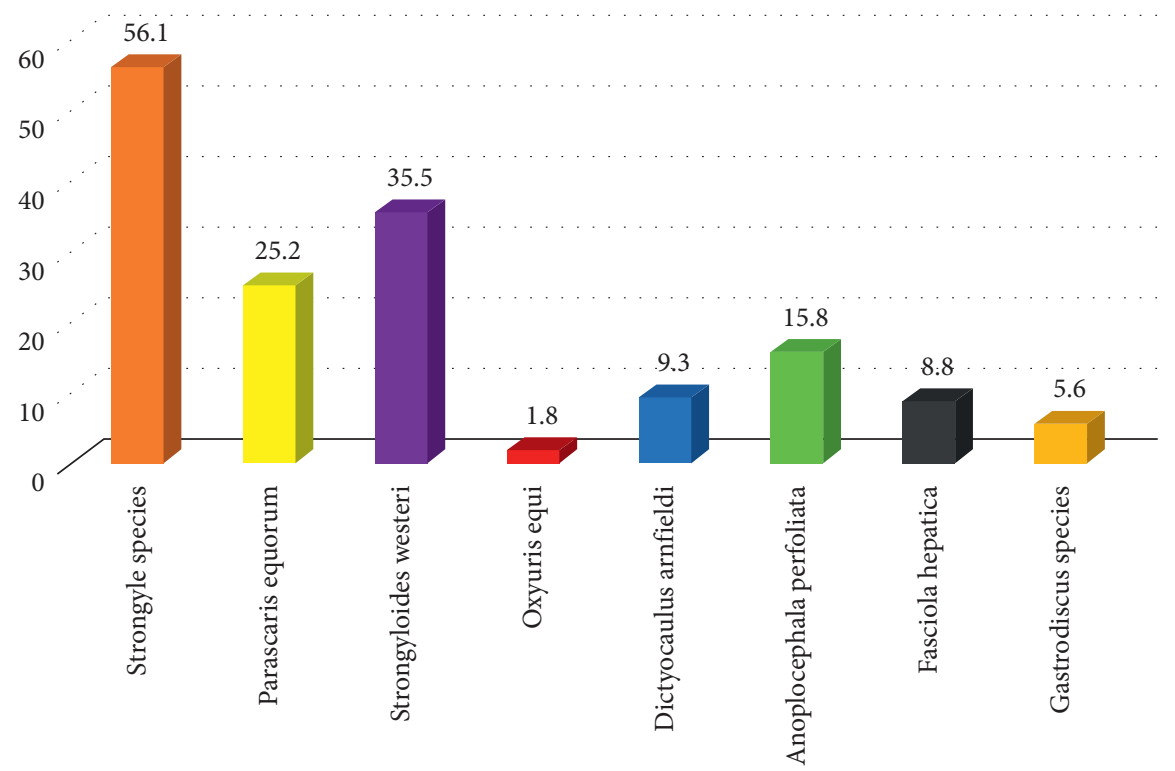

FIgURE 2: Proportion of different species of GI helminths identified in the study area.

TABle 2: Distribution of species of GI helminths identified from donkeys and horses.

\begin{tabular}{|c|c|c|c|c|}
\hline \multirow{3}{*}{ Parasites species } & \multicolumn{4}{|c|}{ Species of animal } \\
\hline & \multicolumn{2}{|c|}{ Donkeys $(n=112)$} & \multicolumn{2}{|c|}{ Horses $(n=102)$} \\
\hline & No. of positives & Prevalence $(\%)$ & No. of positives & Prevalence $(\%)$ \\
\hline Strongyle species. & 74 & 66 & 46 & 45.1 \\
\hline Parascaris equorum & 39 & 34.8 & 15 & 14.7 \\
\hline Strongyloides westeri & 56 & 50 & 20 & 19.6 \\
\hline Oxyuris equi & 10 & 8.9 & 10 & 9.8 \\
\hline Dictyocaulus arnfieldi & 4 & 3.5 & 0 & 0.0 \\
\hline Anoplocephala perfoliata & 18 & 16.1 & 16 & 15.7 \\
\hline Fasciola hepatica & 5 & 4.5 & 14 & 13.7 \\
\hline Gastrodiscus species & 5 & 4.5 & 7 & 6.8 \\
\hline
\end{tabular}

TABLe 3: Prevalence GI parasites in association with risk factors of equine.

\begin{tabular}{|c|c|c|c|c|c|}
\hline Variable & Category & Total & Positive & $\begin{array}{c}X^{2} \\
\text { value }\end{array}$ & $\begin{array}{c}p \\
\text { value }\end{array}$ \\
\hline \multirow{2}{*}{ Species } & Donkey & 112 & 103 & \multirow{2}{*}{25.23} & \multirow{2}{*}{0.0001} \\
\hline & Horse & 102 & 65 & & \\
\hline \multirow{3}{*}{$\begin{array}{l}\text { Body condition } \\
\text { score }\end{array}$} & Good & 60 & 47 & \multirow{3}{*}{8.26} & \multirow{3}{*}{0.016} \\
\hline & Medium & 94 & 81 & & \\
\hline & Poor & 60 & 40 & & \\
\hline \multirow{2}{*}{ Age } & Young & 36 & 27 & \multirow{2}{*}{0.32} & \multirow{2}{*}{0.575} \\
\hline & Adult & 178 & 141 & & \\
\hline \multirow{2}{*}{ Sex } & Male & 157 & 126 & \multirow{2}{*}{1.07} & \multirow{2}{*}{0.301} \\
\hline & Female & 57 & 42 & & \\
\hline \multirow{2}{*}{ Feed type } & Roughage & 62 & 43 & \multirow{2}{*}{4.33} & \multirow{2}{*}{0.037} \\
\hline & Concentrate & 152 & 125 & & \\
\hline \multirow{2}{*}{$\begin{array}{l}\text { Housing } \\
\text { condition }\end{array}$} & Good & 149 & 113 & \multirow{2}{*}{2.07} & \multirow{2}{*}{0.151} \\
\hline & Poor & 65 & 55 & & \\
\hline \multirow{2}{*}{ Water source } & Tap water & 65 & 55 & \multirow{2}{*}{2.07} & \multirow{2}{*}{0.151} \\
\hline & Well water & 149 & 113 & & \\
\hline
\end{tabular}

96.9\% and $97.9 \%$ in donkeys and horses. This difference might be due to the nutritional status of the animal in the respective study area which can influence the level of immunity to be infected by the parasite. Additionally, it could be affected by the deworming habit of the equine and accessibility to the veterinary clinic. Also, there was a statistically significant difference $(p<0.05)$ with the prevalence of GI parasites and feed which was in agreement with the work of Mezgebu et al. [14].

In this study, a relatively higher prevalence of gastrointestinal parasites was recorded in donkeys $(97.1 \%)$ than horses (81\%). This was comparable with the previous finding of Debere et al. [31], who reported higher gastrointestinal parasites in donkeys (95.4\%) than horses (89.7\%), and Tolossa and Ashenafi [7] in donkeys (97.13\%) than in horses $(80.95 \%)$. The observed higher parasitism in donkeys could be attributed to the fact that less attention was given to these animals. Also, it might be related to the feeding practices as all donkeys under the study were at free grazing that they have a high chance of ingesting large amount of gastrointestinal parasite eggs and larvae.

The prevalence of Strongyle species in horses was $45.1 \%$ in the current study which was lower than the previous reports described by Mezgebu et al. [14] who reported 66.7\% prevalence in Gondar Town and Uslu and Guçlu [39] who reported $100 \%$ in Konya, Turkey. The lower prevalence in 
TAвLE 4: Frequency of GI helminths in donkeys and horses after fecal culture.

\begin{tabular}{lcccc}
\hline \multirow{2}{*}{$\begin{array}{c}\text { Species of parasites } \\
\end{array}$} & Donkeys $(n=30)$ & \multicolumn{2}{c}{ Species of animal } & \multicolumn{2}{c}{ Horses $(n=30)$} \\
& No. of harvested larvae & Prevalence (\%) & No. of positives & Prevalence (\%) \\
\hline Strongylus vulgaris & 8 & 26.6 & 11 & 36.6 \\
Strongylus edentatus & 4 & 13.3 & 3 & 10 \\
Cyathostomins species & 13 & 43.3 & 19 & 63.3 \\
\hline
\end{tabular}

the present study could be because all horses of this study were less exposed and, in some cases, totally restricted from pasture.

The prevalence of Strongyle-type infestation in donkeys was $66.07 \%$. This result disagreed with studies conducted in different areas with $87.8 \%$ by Mezgebu et al. [14] in Gondar Town, $76 \%$ by Tesfu et al. [12] in Hawassa, $80.2 \%$ by Asefa and Dulo [40] in Bishoftu, 79.7\% by Abdulahi et al. [41] in Jigjiga, $81 \%$ by Uslu and Guçlu [39] in Konya, Turkey, and $99.5 \%$ by Naramo et al. [42] in Alage, south-western Ethiopia.

The current prevalence of Strongyloides westeri in the horses was $19.6 \%$ which was in agreement with the work of Ibrahim et al. [37] who reported 20\% prevalence in Hawassa town, Southern Ethiopia. However, a higher prevalence was observed as compared with the previous report by Belete and Derso (2015) in Mekelle and Uslu and Guçlu [39] in Konya who reported the prevalence of $0.8 \%$ and $7.2 \%$, respectively. This might be because patent infections develop primarily by transmammary infection of foals of Strongyloides westeri in the study area. Its prevalence in donkeys was $50.0 \%$ which is higher than in the report of Uslu and Guçlu [39] in Konya, Getahun and Kassa [43] in Tenta woreda, Gebreyohans et al. (2017) in and around Mekelle, and Ibrahim et al. (2011) in Hawassa with the prevalence of $12.3 \%, 9.5 \%, 2 \%$, and $20 \%$, respectively.

The prevalence of Parascaris in horse under this study was $14.7 \%$ which was lower than in the reports of Berhanu et al. [38] (55.8\%) in Hawassa town, Mezgebu et al. [14] $(43.8 \%)$ in Gondar town, $32.8 \%$ by Chemeda et al. [44] in and around Ambo Town, and 25\% by Asefa and Dulo [40] in Bishoftu town. On the other hand, the prevalence of Parascaris in the present study was higher than in the previous report by Tesfu et al. (2014) in Hawassa Town, Uslu and Guçlu [39] in Konya, and Belete and Derso [45] in Mekelle with the infestation rate of $4.6 \%, 10.8 \%$, and $1.8 \%$, respectively.

In donkeys, the prevalence of Parascaris was found to be $34.8 \%$ which was higher than the prevalence reported by Getahun and Kassa [43] (11.2\%) in Tenta woreda, $6.4 \%$ by Gebreyohans et al. [46] in and around Mekelle, $26.2 \%$ by Tesfu et al. [12] in Hawassa Town, $15.1 \%$ by Asefa and Dulo, [40] in Bishoftu Town, and 9.8\% by Uslu and Guçlu [39] in Konya. Conversely, it was lower than in reports described by Naramo et al. [42], Ibrahim et al. [37], Abdulahi et al. [41], and Mezgebu et al. [14] who represented a prevalence of $53.6 \%, 52.8 \%, 44.8 \%$, and $42.3 \%$ in donkeys, respectively. All this difference might be because this parasite was found to be persistent generally in low numbers in the pasture despite their parasite control programs applied in recent years.
The current prevalence of Oxyuris equi in horses was $9.8 \%$ which was nearly in agreement with the prevalence reported by Uslu and Guçlu [39] (8.8\%) in Konya, 8.7\% by Asefa and Dulo [40] in Bishoftu, $8.8 \%$ by Belete and Derso [45] in Mekelle, and $11.2 \%$ by Chemeda et al. [44] in and around Ambo Town. However, it was higher than reports described $0.4 \%$ by Mezgebu et al. [14] in Gondar and 1.8\% by Uslu and Guçlu [39] in Konya. In the current study, the prevalence of Oxyuris equi in donkeys were $8.9 \%$, which showed a significantly higher prevalence as compared with other studies mentioned by Mezgebu et al. [14] in and around Gondar, Asefa, and Dulo [40] in Bishoftu Town, Uslu and Guçlu [39] in Konya, and Getahun and Kassa [43] in Tenta Woreda with the prevalence of $4.3 \%, 5.2 \%, 1.2 \%$, and $2.7 \%$, respectively. This is somewhat conflicting and this could be due to compromised immune responses relating to concurrent disease, but it needs further investigation.

The current prevalence of Fasciolosis in horses was $13.7 \%$, which disagreed with the work of Ayana et al. [47] who reported $24 \%$ prevalence in Holeta town. Although the prevalence of Fasciolosis in donkeys were found to be $4.5 \%$ which was nearly agreed with the results of Abdulahi et al. [41] from Jigjiga, Gebreyohans et al., [46] in and around Mekelle, and Getahun and Kassa [43] in Tenta Woreda who reported $1.6 \%, 2.2 \%$, and $2 \%$ prevalence, respectively. However, the higher prevalence was reported by Uslu and Guçlu [39] in Konya and Mezgebu et al. [14] in Gondar Town who reported $6.2 \%$ and $5.7 \%$ prevalence, respectively.

The prevalence of Anoplocephala perfoliata in horses was $15.7 \%$ which is higher than the prevalence reported in $2.7 \%$ by Uslu and Guçlu [39], 2\% by Belete and Derso [45], and $1.6 \%$ by Chemeda et al. [44]. Also, the prevalence of Anoplocephala perfoliata in donkeys was $16.1 \%$ which showed a higher infestation rate as compared with $6.2 \%$ by Uslu and Guçlu [39], 2.6\% by Getahun and Kassa [43], and 2.7\% by Gebreyohans et al. [46].

In the present study, Dictyocaulus arnfieldi was not observed in the horse. However, its prevalence in donkeys was $3.6 \%$ which agreed with the previous report by Ibrahim et al. [37], who reported the $3.6 \%$ prevalence in Hawassa town, southern Ethiopia.

The current prevalence of Gastrodiscus species was $6.8 \%$ and $4.5 \%$ in horses and donkeys, respectively. These results were higher than Mezgebu et al. [14] who reported 2.9\% and $3.6 \%$, respectively, in Gondar. However, the result was lower than the prevalence reported by Ayana et al. [47] in Holeta Town, Oromia, Central Ethiopia, who reported $13.7 \%$ in horses and $10.6 \%$ in donkeys. 
From the coproculture study, the present study revealed that Cyathostomins species was highly prevalent than $S$. vulgaris and S. edentatus with a prevalence of $43.3 \%$ and $63.3 \% ; 26.6 \%$ and $36.6 \%$; and $13.3 \%$ and $10 \%$ in donkeys and horses, respectively. This higher prevalence of cyathostomins species in the present studies was in agreement with Uslu and Guçlu [39].

\section{Conclusions and Recommendations}

Internal parasites are important health problems of equines in the study area with an overall prevalence of $78.5 \%$, especially the highest in donkeys with $92 \%$ followed by horses (63\%). Factors such as species, body condition, and feed type were strongly associated $(p<0.05)$ with the occurrence of the disease. Strongyle species (56.1\%), Parascaris equorum (25.2\%), Strongyloides westeri (35.5\%), Oxyuris equi (9.3\%), Dictyocaulus arnfieldi (1.8\%), Anoplocephala perfoliate, (15.8\%), Fasciola hepatica (8.8\%), and Gastrodiscus species (5.6\%) were the most dominant gastrointestinal parasites affecting horse and donkeys in the study area. The coproculture investigation revealed that Strongylus vulgaris (36.6\%) and Cyathostomins species (36.6\%) were recorded commonly in horses as compared to donkeys, whereas a higher proportion of Strongylus edentatus (13.3\%) was recovered from donkey than horses.

In conclusion, in order to minimize losses attributed to the equine internal parasites in the area, equine owners should be informed of the economic importance and methods of control and prevention of helminths of equines through management improvements. Furthermore, regular and strategic deworming programs with efficacious anthelmintics should be carried out regularly.

\section{Abbreviations}

GI: Gastrointestinal.

\section{Data Availability}

The datasets used and analyzed during the current study are available from the corresponding author on request.

\section{Ethical Approval}

Ethical approval for this research was obtained from the Wolaita Sodo University Research Ethics and Review Committee.

\section{Consent}

Before collecting samples, verbal consent was also pursued from the equine owners to take fecal samples from their equine, and strict hygienic measures were adopted.

\section{Conflicts of Interest}

All authors declare no conflicts of interest.

\section{References}

[1] F. Marshall and J. M. Capriles, "Animal domestication and pastoralism: socio-environmental contexts," in Encyclopedia of Global ArchaeologySpringer International Publishing, Berlin, Germany, 2018.

[2] H. Disassa, A. Alebachew, and G. Kebede, "Prevalence of Strongyle infection in horses and donkeys in and around dangila town, northwest Ethiopia," Acta Parasitologica Globalis, vol. 6, pp. 14-19, 2015.

[3] A. Gelaye and H. Fesseha, "Assessment of socio-economic importance and major constraints of working equines in and around debre berhan town, Central Ethiopia," Veterinary Medicine-Open Journal, vol. 5, no. 2, pp. 30-38, 2020.

[4] S. Moltumo, M. Mathewos, H. Fesseha, and M. Yirgalem, "Assessment of welfare problems on working donkeys in Hosaena district, Hadiya zone, southern Ethiopia," Veterinary Medicine-Open Journal, vol. 5, no. 1, pp. 14-20, 2020.

[5] Central Statistical Agency, "Report on livestock and livestock characteristics," in The federal democratic republic of ethiopia, private peasant holdings, statistical bulletin 570CSA, Ababa, Ethiopia, 2017.

[6] FAOSTAT, Food and Agricultural Organization of The United Nation, FAO, FAOSTAT Data, Food and Agricultural Organization, Rome, Italy, 2012.

[7] Y. H. Tolossa, "Epidemiological study on gastrointestinal helminths of horses in arsi-bale highlands of oromia region, Ethiopia," Ethiopian Veterinary Journal, vol. 17, pp. 51-62, 2013.

[8] A. Seyoum, G. Birhan, and T. Tesfaye, "Prevalence of workrelated wound and associated risk factors in cart mules of adet town, north-western Ethiopia," American-eurasian Journal of Scientific Research, vol. 10, pp. 264-271, 2015.

[9] S. Tesfaye, B. Deressa, and E. Teshome, "Study on the health and welfare of working donkeys in mirab abaya district, southern Ethiopia," Academic Journal of Animal Diseases, vol. 5, pp. 40-52, 2016.

[10] H. Fesseha, A. Ayele, and E. Goa, "Assessment on ocular problems of cart donkey in and around Wolaita Sodo, southern Ethiopia," Austin Journal of Veterinary Science \& Animal Husbandry, vol. 7, p. 1067, 2020.

[11] G. Ayele, F. Gebreab, B. Endebu, and A. Joe, "Prevalence of gastrointestinal parasites of donkeys in Dugda Bora district, Ethiopia," Livestock Research for Rural Development, vol. 18, pp. 2-6, 2006.

[12] N. Tesfu, B. Asrade, R. Abebe, and S. Kasaye, "Prevalence and risk factors of gastrointestinal nematode parasites of horse and donkeys in Hawassa town, Ethiopia," Journal of Veterinary Science \& Technology, vol. 5, pp. 2157-7579, 2014.

[13] J. R. Pereira and S. S. S. Vianna, "Gastrointestinal parasitic worms in equines in the paraíba valley, state of são paulo, Brazil," Veterinary Parasitology, vol. 140, no. 3-4, pp. 289-295, 2006.

[14] T. Mezgebu, K. Tafess, and F. Tamiru, "Prevalence of gastrointestinal parasites of horses and donkeys in and around gondar town, Ethiopia," Open Journal of Veterinary Medicine, vol. 3 , no. 6 , p. $267,2013$.

[15] R. Fikru, D. Reta, S. Teshale, and M. Bizunesh, "Prevalence of equine gastrointestinal parasites in Western highlands of Oromia," Bulletin of Animal Health and Production in Africa, vol. 53, pp. 161-166, 2005.

[16] M. Valdez-Cruz, M. Hernandez-Gil, L. Galindo-Rodriguez, and M. Alonso-Diaz, "Gastrointestinal parasite burden, body condition and haematological values in equines in the humid tropical areas of Mexico," in Proceedings of the Fifth 
International Colloquium on Working Equines. The Future for Working Equines, pp. 62-72, Addis Ababa, Ethiopia, November 2006.

[17] F. Gebreab, "Helminth parasites of working equids; the African perspective," in Proceedings of the 8th international conference on infectious disease of equines, pp. 318-324, Dubai, UAE, March 1998.

[18] M. Getachew, A. Trawford, G. Feseha, and S. W. J. Reid, "Gastrointestinal parasites of working donkeys of Ethiopia," Tropical Animal Health and Production, vol. 42, no. 1, p. 27, 2010.

[19] F. A. Burden, N. Du Toit, M. Hernandez-Gil, O. Prado-Ortiz, and A. F. Trawford, "Selected health and management issues facing working donkeys presented for veterinary treatment in rural Mexico: some possible risk factors and potential intervention strategies," Tropical Animal Health and Production, vol. 42, no. 4, pp. 597-605, 2010.

[20] N. Du Toit, F. A. Burden, and P. M. Dixon, "Clinical dental findings in 203 working donkeys in Mexico," The Veterinary Journal, vol. 178, no. 3, pp. 380-386, 2008.

[21] D. Sheferaw and M. Alemu, "Epidemiological study of gastrointestinal helminths of equines in damot-gale district, wolaita zone, Ethiopia," Journal of Parasitic Diseases, vol. 39, no. 2, pp. 315-320, 2015.

[22] H. Fesseha, S. Aliye, T. Kifle, and M. Mathewos, "Chemical and drug use in dairy farms of Hawassa town, southern Ethiopia," Public Health-Open Journal, vol. 5, no. 1, pp. 1-7, 2020.

[23] E. K. Gedecho, "Urban tourism potential of Hawassa city, Ethiopia," American Journal of Tourism Research, vol. 4, pp. 25-36, 2015.

[24] W. E. Loch and M. Bradley, Determining Age of Horses by Their Teeth, Extension publications (MU), , MI, USA, 1998, https://en.wikipedia.org/wiki/Kansas_City,_Missouri.

[25] D. Elisabeth, The Professional Hand Books of the Donkey, Whittet Books Limited, London, UK, 4th edition, 2008.

[26] M. Thrusfield, Veterinary Epidemiology, John Wiley \& Sons, Hoboken, NJ, USA, 2018.

[27] E. Soulsby, Helminths, Arthropods and Protozoa of Domesticated Animals, ELBS and Bailliere Tindall, London, UK, 1982.

[28] A. M. Zajac and G. A. Conboy, Veterinary Clinical Parasitology, John Wiley \& Sons, Hoboken, NJ, USA, 2012.

[29] E. C. Greiner, "Parasite diagnosis by fecal examination," Journal of the Association of Avian Veterinarians, vol. 3, no. 2, pp. 69-72, 1989.

[30] W. J. Foreyt, Veterinary Parasitology Reference Manual, Wiley, Hoboken, NJ, USA, 2013.

[31] D. Debere, Y. Muktar, S. Shiferaw, and D. Belina, "Internal parasites of equines and associated risk factors in and around Guder town, West Shewa, central Ethiopia," Ethiopian Veterinary Journal, vol. 22, no. 2, pp. 36-52, 2018.

[32] H. Fesseha, M. Mathewos, and F. Kidanemariam, "Anthelmintic efficacy of Strongyle nematodes to ivermectin and fenbendazole on working donkeys (Equus asinus) in and around hosaena town, southern Ethiopia," Veterinary Medicine International, vol. 2020, Article ID 4868797, 7 pages, 2020.

[33] B. Takele and E. Nibret, "Prevalence of gastrointestinal helminthes of donkeys and mules in and around Bahir Dar, Ethiopia," Ethiopian Veterinary Journal, vol. 17, pp. 13-30, 2013.

[34] R. Chemeda, N. Mekonnen, Y. Muktar, and W. Terfa, "Study on prevalence of internal parasites of horses in and around
Ambo town, Central Ethiopia," American-eurasian Journal of Agricultural \& Environmental Sciences, vol. 16, pp. 1051-1057, 2016.

[35] D. Gulima, "Epidemiological study of helminthosis in traction horses in Awi zone, Northwestern, Ethiopia," Ethiopian Veterinary Journal, vol. 10, pp. 37-54, 2006.

[36] Z. Seyoum, M. Tesfaye, and S. Derso, "Prevalence, intensity and risk factors of infestation with major gastrointestinal nematodes in equines in and around Shashemane, Southern Ethiopia," Tropical Animal Health and Production, vol. 47, no. 8, pp. 1515-1521, 2015.

[37] N. Ibrahim, T. Berhanu, B. Deressa, and T. Tolosa, "Survey of prevalence of helminth parasites of donkeys in and around Hawassa town, Southern Ethiopia," Global Veterinaria, vol. 6, pp. 223-227, 2011.

[38] T. Berhanu, N. Ibrahim, B. Deressa, and T. Tolosa, "Prevalence of helminth parasites of horses in and around Hawassa town, southern Ethiopia," Acta Parasitological Globalis, vol. 5, pp. 7-11, 2014

[39] U. Uslu and F. Guclu, "Prevalence of endoparasites in horses and donkeys in Turkey," Bulletin-Veterinary Institute in Pulawy, vol. 51, p. 237, 2007.

[40] S. Asefa and F. Dulo, "A prevalence of gastro-intestinal nematode parasitic infections in horses and donkeys in and around Bishoftu town, Ethiopia," Middle-East Journal of Applied Sciences, vol. 3, pp. 38-43, 2017.

[41] M. Abdulahi, H. Kefyalew, and Y. Muktar, "Major gastrointestinal parasites of donkey in and around Jigjiga, somali region, Ethiopia," Advances in Biological Research, vol. 11, pp. 144-149, 2017.

[42] M. Naramo, Y. Terefe, J. Kemal, T. Merga, G. Haile, and M. Dhaba, "Gastrointestinal nematodes of donkeys in and around Alage, South-Western Ethiopia," Ethiopian Veterinary Journal, vol. 20, pp. 87-97, 2016.

[43] T. K. Getahun and T. Z. Kassa, "Prevalence and species of major gastrointestinal parasites of donkeys in Tenta woreda, amhara regional state, Ethiopia," Journal of Veterinary Medicine and Animal Health, vol. 9, pp. 23-31, 2017.

[44] R. Chemeda, N. Mekonnen, Y. Muktar, and W. Terfa, "Study on prevalence of internal parasites of horses in and around Ambo town, Central Ethiopia," American-Eurasian Journal of Agricultural and Environmental Sceince, vol. 16, pp. 10511057, 2016.

[45] S. Belete and S. Derso, "Prevalence of major gastrointestinal parasites of horses in and around Mekelle (Quiha and Wukro)," World Journal of Animal Science Research, vol. 3, pp. 1-10, 2015.

[46] A. Gebreyohans, A. Abrhaley, and E. Kebede, "Prevalence of gastrointestinal helminthes of donkey in and around Mekelle," National Science, vol. 15, pp. 42-57, 2017.

[47] D. Ayana, F. Birhan, H. Ashenafi, and H. Waktole, "Trematode parasites of equine in and around Holeta town, Oromia, Central Ethiopia," European Journal of Biological Sciences, vol. 9, pp. 193-198, 2017. 